\title{
Spatial Intra-Annual Variability of Precipitation Based on Geostatistics. A Case Study for the Paraiba Do Sul Basin, Southeastern Brazil
}

\author{
Walquiria Marins Silva, Silvio Jorge C. Simões \\ Environmental Engineering Department, Institute of Science and Technology, Sao Paulo State University \\ (UNESP), São José dos Campos, Brazil \\ Email: silvio.simoes@ict.unesp.br
}

Received 24 January 2014; revised 25 February 2014; accepted 21 March 2014

Copyright (C) 2014 by authors and Scientific Research Publishing Inc.

This work is licensed under the Creative Commons Attribution International License (CC BY). http://creativecommons.org/licenses/by/4.0/

(c) (i) Open Access

\begin{abstract}
The emphasis in this research is to evaluate the spatial distribution of the precipitation using a geostatistics approach. Seasonal time scales records considering DJF, MAM, JJA e SON periods performed the analysis. Procedures to evaluate the variogram selection and to produce kriging maps were performed in a GIS environment (ArcGIS ${ }^{\circledR}$ ). The results showed that kriging method was very suitable to detect both large changes in the whole area as those local small and subtle changes. Kriging demonstrated be a powerful statistical interpolation method that might be very useful in regions with great complexity in climatology and geomorphology.
\end{abstract}

\section{Keywords}

Spatial Rainfall, Semivariogram, Kriging, Hydroclimatologic Analysis

\section{Introduction}

Precipitation is a process, which usually has a high spatial and temporal variability at the watershed scale. The scientific evidences that global change predicts a scenario that leads to an increase in extreme weather events [1] added to the spatial analysis of precipitation an even greater importance due to the need of understanding the large variability of intra and inter-annual regional precipitation [2]-[9].

The accurate measurement of rainfall—and its spatial distribution—requires the installation of dense sensor networks, representing high costs of implementation and operation [10]. On the other hand, it is useful to choose 
a spatial interpolation method for estimating rainfall—a continuous variable—where no direct measurements are available.

The four main sub-fields related to the physical world (atmosphere, hydrosphere, lithosphere and biosphere) widely make the use of geostatistics approach for describing the variability of spatial patterns. Kriging is part of geostatistical approach, which search to exhibit a structure of spatial correlation based a powerful and consistent probabilistic method. In atmosphere sub-field, for example, applications are found associated with climatology, temperature, rainfall, historic sea-level rise and atmosphere pollution [11]-[17].

Several studies compare kriging with other interpolation methods, such as thiessen, inverse distance weighting and splines. Among all the spatial interpolation methods kriging is the most convincing because is based on good theoretical principles [18] and because consider the uncertainty factors that occur in complex natural systems.

Estimation of rainfall using geostatistical tools provides more accurate results than other interpolation methods. Moreover, the possibility of quantifying the uncertainties using geostatistics approach is particularly suitable for comparison with estimates of rainfall produced by other means and methods (e.g., radar, satellite and climate models) [19].

Therefore, this paper intends to evaluate the intra-annual spatial variability of rainfall over the Paraíba do Sul River basin (Portion of Sao Paulo state), Southeastern Brazil using a geoestatistical approach which operates within a Geographic Information Systems (GIS). The Paraiba do Sul basin-linking the major metropolitan center of Sao Paulo and Rio de Janeiro-was selected as a case study area for two reasons: its importance for Brazilian regional development and the availability of a dense regional rain gauge network with a significant and relatively updated time series data.

\section{Material and Method}

\subsection{Study Area Characteristics}

The study area corresponds to the upper section of the Paraiba do Sul basin (Sao Paulo State portion), comprising nearly 15,300 $\mathrm{km}^{2}$ and situated in the Southeastern of Brazil (Figure 1). The basin is characterized by heterogeneous geomorphology, hydrology and soils with elevations varying from about $400 \mathrm{~m}$ in extent alluvial plains up to more than $2400 \mathrm{~m}$ in the Mantiqueira and Serra do Mar mountain ridges.

Paraiba do Sul basin has a large importance in the history, culture and economy of Southeastern Brazil with high urbanization rate and industrial activities along the main river. In this context, water availability management is very important for regional development and urban growth. This region is one of the country's most dynamic economic areas. Because of its strategic location-among the states of São Paulo, Minas Gerais, and Rio de Janeiro - the river basin currently accounts for approximately 11\% of national gross domestic product (GDP).

Historically, human activity imposed dramatic transformations of the regional landscape. The reduction in forested areas reached from nearly $81 \%$ to $8.0 \%$ over the last 300 years [20]. Using the principles of landscape

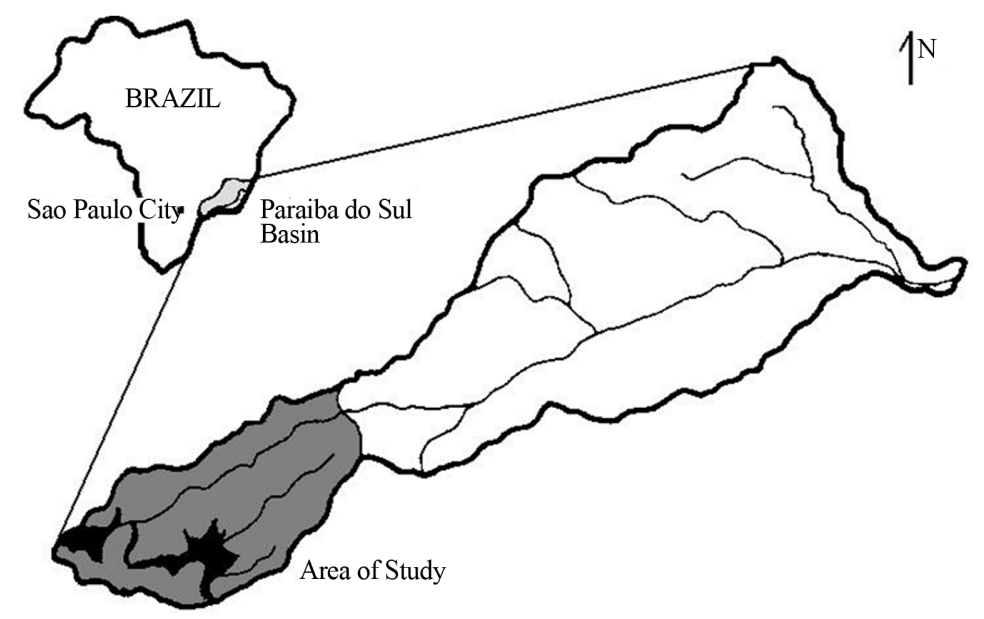

Figure 1. Study area (Paraiba do Sul basin—São Paulo State). 
ecology [21], the matrix that forms the landscape correspond to grazing where occur patches of isolated forest fragments, eucalyptus plantation and urban areas. In the last years, has occurred the expansion of the Eucalyptus plantation mainly occupying the degraded pasture areas. On the other hand, cities continue to expand near, or on alluvial plains, occupying a significant part of the floodplain contributing to the reduction and elimination of natural wetland ecosystems.

Because of its strategic geographical position, multi-purpose reservoirs (for electricity generation, flood control and flow regulation) were built first in the 1950s, and later in the 1970s. Since 1952, water from the Paraíba do Sul River is diverted into the Guandu River in the Rio de Janeiro state. About 8.7 million people living in Rio de Janeiro Metropolitan Region depend on Paraiba do Sul basin for water supply.

In the study area, mean river discharge is $217 \mathrm{~m}^{3} / \mathrm{s}$; the largest withdrawals of water are made for agricultural irrigation $10.4 \mathrm{~m}^{3} / \mathrm{s}$, followed by industrial use, $6.5 \mathrm{~m}^{3} / \mathrm{s}$ and, domestic use, $3.4 \mathrm{~m} / 3$ [ [22]. Therefore, the Paraiba do Sul River is an example of a complex multipurpose water resources management that links hydropower production to agricultural, industrial and domestic water use.

\subsection{Database}

Several topographic and thematic maps and database are available in the study area (ArcGIS ${ }^{\circledR}$ and AutoCAD ${ }^{\circledR}$ formats). Digital topographic maps include surveys at 1:250,000 and 1:50,000 scales covering the total basin. This level of topographic scale is suitable and represents a better situation that those found in other Brazilian regions. The Digital Elevation Model (DEM) and the others thematic maps were derived from a topographic map at 1:250,000 scale, 30-by-30 minute quadrangle IBGE maps.

The hydrological data include a network of 107 rain gauges installed at a variety of altitudes (450 m - 1700 $\mathrm{m}$ ), some of which have been in place since the 1930's. Stations with less than 30 years of data and with more than $5 \%$ of missing data were excluded from this study. Based on these principles, 40 rainfall gauges were selected for detailed statistical and geostatistical analysis. The Figure 2 presents the locations of the selected rainfall stations associated with a TIN model of the study area using Spatial Analyst ${ }^{\circledR}$ extension in the ArcGIS ${ }^{\circledR}$ environment.

\subsection{Methodological Procedures}

Since geostatistics treats a set of spatial data as a sample from a random process, it is able to provide estimates in a context governed by a natural phenomenon such as hydrologic variables. It assumes that the values of these variables are auto-correlated spatially, such that samples close together in space are more alike than those that

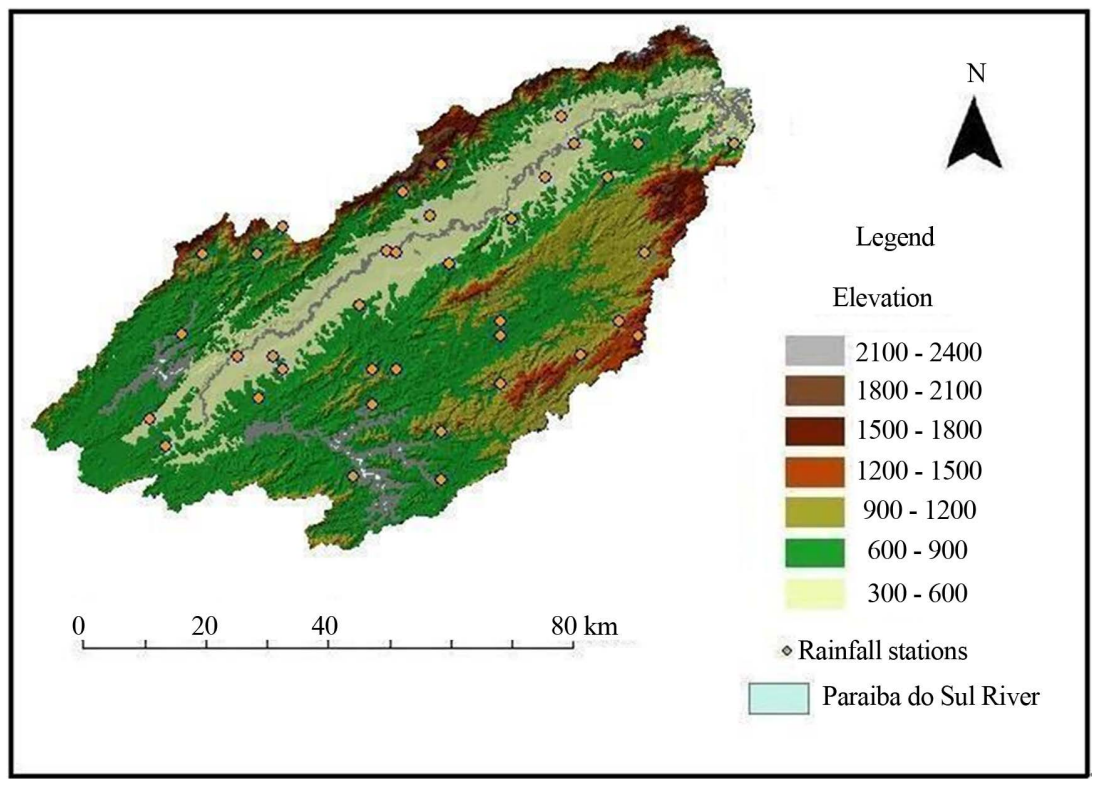

Figure 2. Selected rainfall stations associated with a TIN model. 
are further apart [23].

Geostatistics uses the semivariogram as one of its primary tools to measure the spatial variability of a regionalized variable and provides the input parameters for the spatial interpolation of kriging [24]. The semivariogram is, therefore, used in the first steps of spatial prediction to investigate the relationship of the distribution of variable $(z(x))$ in space. This tool is able to measure the degree of spatial dependence between samples over a specific support. The expected squared difference between paired data values $\{z(x)$ and $z(x+\boldsymbol{h})\}$ to the lag distance $\boldsymbol{h}$ assumes stationary in increments. The term stationary means that the distribution of the random process has certain attributes that are the same everywhere [25].

To obtain an estimate of the parameters, a theoretical semivariogram model is selected to define the weights of the kriging function. On the other hand, semivariograms can be calculated for a variety of directions to allow the recognition of possible anisotropic variability structure. One can formulate an estimator for the semivariogram as follows:

$$
2 \hat{\gamma}(\boldsymbol{h})=\frac{1}{|N(h)|} \sum_{i=1}^{N(h)}\left[z\left(x_{i}\right)-z\left(x_{j}\right)\right]^{2}, h \in \mathfrak{R}^{d}
$$

where: $h$ is a vector, $|N(h)|$ is the number of distinct elements of $N(h)$, which is given by:

$$
N(\boldsymbol{h}) \equiv\left\{\left(x_{i}, x_{j}\right): x_{i}-x_{j}=\boldsymbol{h} ; i, j=1, \cdots n\right\}
$$

When there is spatial dependence, usually the closest two measures are more alike than two others that are further apart, allowing $\gamma(\boldsymbol{h})$ to increase as the distance $\boldsymbol{h}$ increases too. However, from a certain distance, it will not find related values with $z(\boldsymbol{h})$ because the spatial correlation between the samples ceases to exist [26]. The semivariogram point where the data present no spatial dependence, maintained around the same semi-variance (y axis) and where it is established a straight line in the graph, called the "sill" (C) as depicted in Figure 3. The distance from the origin ( $x$ and $y$ coordinates equals zero) to the sill, is called the "range" (a), which represents the radius of influence of sampling points on its neighborhood, indicated by the distance at which the variance stabilizes.

After selecting the best variogram model, we can use kriging for modeling fine-scale variability of a regional watershed scale. Kriging is a set of linear regression routines that minimizes estimation variance from a predefined covariance model which takes into account stochastic dependence among the data distributed in space [28] [29].

There are three techniques to perform kringing: ordinary, simple and universal kriging. In this research is used ordinary kriging, which relies on spatial correlation structure of the data to determine the weighting values. This approach uses information from the theoretical semivariogram model to find the optimal weights to be associated with points with known values (sampled points), allowing estimate the unknown points. In other words, it is understood as a series of techniques of regression analysis that seeks to minimize the estimated variance from a previous model.

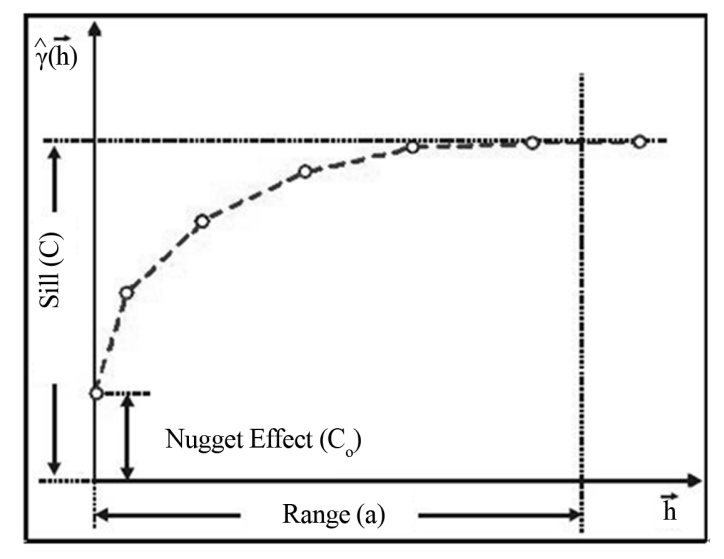

Figure 3. Parameters of the semivariogram [27]. 
The difference between kriging and other methods of interpolation is the way the weights are distributed in the different samples. For traditional methods (or deterministic ones), such as Simple Linear Interpolation, all samples have weights equal to $1 / \mathrm{N}$ ( $\mathrm{N}$ being the total number of samples). In another deterministic method, the Inverse Distance Weighting (IDW), the weights given to samples are related to the inverse of the distance that separates the estimated to the observed values.

\section{Results and Discussion}

The region presents a high uncertainty in the long-term assessment of water resources. Previous studies have documented the bimodal character of the annual cycle of precipitation in Southeastern Brazil [30] [31] with alternating of dry and wet seasons. This is consistent with the transition from tropical to mid-latitude climate regimes. In the Paraíba do Sul basin, the average annual precipitation is in the order of $1400 \mathrm{~mm}$, but exhibits large inter-annual variability ranging between $800 \mathrm{~mm}$ and $2000 \mathrm{~mm}$. Severe droughts occurred in 1943/1944, 1953-1957, 1963, 1968, 1984, 1994, 1997, 2001 and 2013/2014; whereas 1947, 1976, 1983 and 2000, 20082010 were exceptionally wet years. Dry and wet spells (1 - 2 years) alternate ubiquitously in the observations. In 2001, a severe drought was blamed by the severe reduction in water levels in the reservoirs of many Brazilian hydroelectric power plants [32]. By September, 2001, the reservoirs were working at minimum capacity (about $20 \%$ of the total volume). The shortage period remained until 2004. The rainfall regime has changed abruptly since then. In 2010, São Luis do Paraitinga, a small town located in the northeastern of study area was devastated by a flood, where many historical buildings collapsed. In the last three years, other small and mediumsized towns were affected by floods along the Paraiba do Sul River and its main tributaries.

Besides the variation inter-annual, the region presents a high intra-annual variability. The precipitation in Southeastern Brazil is mainly concentrated during the summer period as showed in Figure 4. It is estimated that approximately $70 \%$ of all annual precipitation falls during December-January-February (DJF) period. Therefore, is very important to analyze the spatial precipitation considering the seasonality, which make possible to reduce the large intra-annual variability.

The kriging analysis allowed observing that—besides the intra-annual temporal variability—a significant spatial variation in rainfall occurs in this region. The resulting images of spatial distribution of rainfall data represent different gray level values. This kind of representation requires that the absolute value of the variable be represented in a scale ranging from 0 (black) to 255 (white). Lighter levels correspond to lowest average rainfall and the darker levels correspond to the highest one (Figure 5).

In the rainy season (DJF), the highest average precipitation is concentrated in the western region of the basin corresponding to the Serra da Mantiqueira Ridge (Figure 5) whose altitudes can reach $2400 \mathrm{~m}$. Another area of high concentration of rainfall is located in the northeastern portion of the basin corresponding to the Bocaina Plateau with altitudes around $1400 \mathrm{~m}$. On the other hand, the region of lowest rainfall rate correspond to the

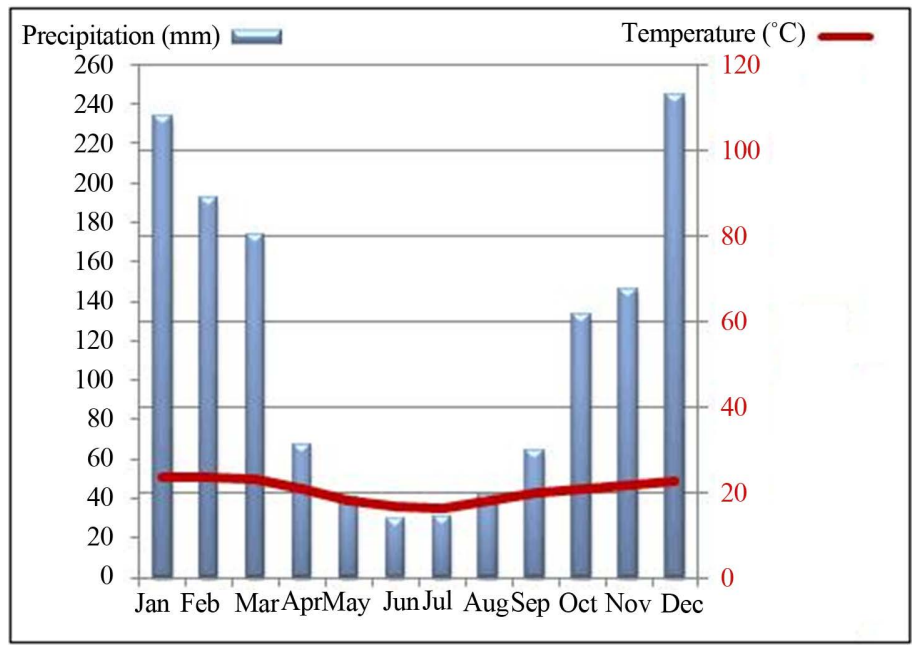

Figure 4. Variability of intra-annual precipitation and temperature of a selected meteorological station. 

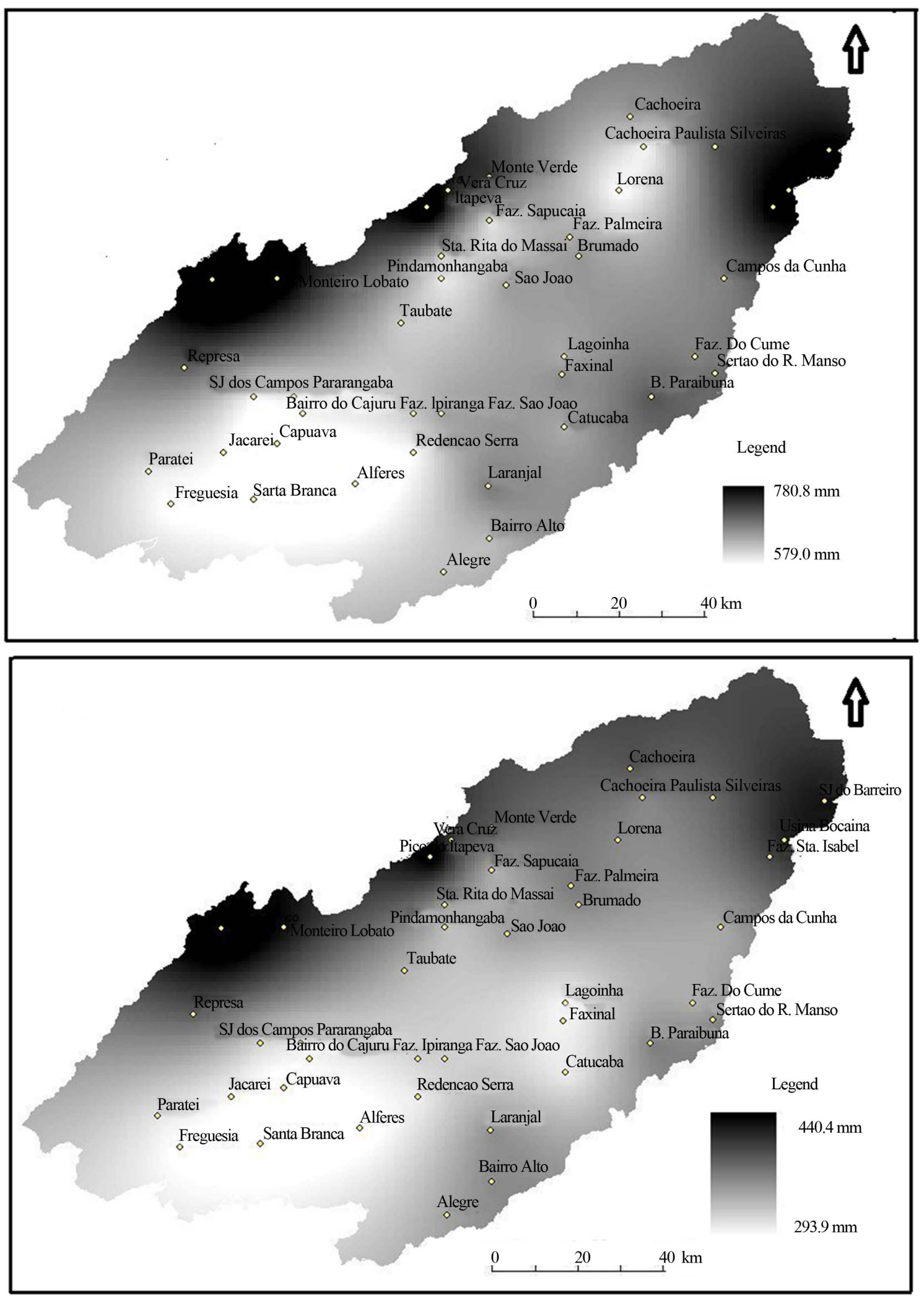

Figure 5. Spatial distribution of rainfall showing areas with higher rainfall (darker shades) and regions with lower rainfall (lighter shades) during the summer (above) and the autumn (below). The maps identify the station names where the rainfall data was collected. 
southern of the basin with altitudes approximately of $780 \mathrm{~m}$ and the center-north of the basin with altitudes varying between 580 and $540 \mathrm{~m}$.

During the autumn (MAM period), the spatial distribution of rainfall (Figure 5) is relatively similar to that observed during the summer (DJF period) mainly on those areas of higher precipitation, which are concentrated in the Serra da Mantiqueira ridge and the Bocaina plateau both situated in the northern of study area. The areas with lowest average rainfall present a small shift in the center of the area when compared with the summer spatial pattern (DJF) (Figure 5).

During the drier season (JJA), on contrary, the kriging analysis showed a significant change on the spatial pattern of rainfall compared to all other seasonal periods (Figure 6). The region with the lowest levels of average precipitation moved from south to north covering a wide surface in the northeastern portion of area. With respect to the regions with higher rainfall, the changes were less pronounced although was observed a significant increase of rainfall in the Serra do Mar Ridge (eastern region).

During the period from September to November (SON) (Figure 6), the spatial pattern of precipitation is very similar to the spatial patterns that occur during DJF and MAM periods (Figure 5). The highest precipitation rates are concentrated in the region of the Serra da Mantiqueira ridge and the Bocaina plateau. The smallest precipitation rates continue to occur in the southern portion of the study area.

An important issue is to understand the reason for the spatial variability of rainfall in the region considering the different annual seasons. Despite of the high climatic and geomorphological complexity, it is possible to make some preliminary considerations about the reasons for the spatial variability of intra-annual rainfall.

The Paraiba do Sul basin is located on the Tropic of Capricorn, which corresponds to an area of transition between the regimes of low latitude tropical and temperate climates of mid latitude. The region has the following regional climates: humid tropical (spring-summer), sub-tropical humid (fall) and tropical semi-arid (winter) [30].

During the summer, when convective processes are more actives, water vapor from the coast to the inland might cause intense rainfall characterizing the phenomenon known as South Atlantic Convergence Zone (SACZ), one of the main phenomena that can influence the rainfall system during this season. On the other hand, during the winter, cold fronts from southeastern Brazil have been considered the main mechanism [33] that generates significant changes and are responsible for instability and abrupt changes in time. Moreover, the spatial distribution of precipitation within the basin is directly related with the orographic role in the production and distribution of rainfall, mainly associated with the parallelism of Serra do Mar and Mantiqueira ridges.

During the summer and in the transition seasons (spring and fall) the highest concentrations of rainfall occur in the headwaters region located in the Serra da Mantiqueira. The predominant mechanism is formed by isolated convection currents, which are responsible for intense rainfall and warm fronts. In the period of greatest dry season (winter), rainfall is mainly caused by frontal system, which are concentrated near the north coast [34]. Therefore, in JJA period, the frontal systems succeed more frequently and with greater speed, causing increased cloud cover mainly on the coast. Consequently, the highest rainfall averages reach both the ridge systems (Serra da Mantiqueira and the Serra do Mar) (Figure 5). On the other hand, the advancement of frontal systems does not have enough energy to reach the intermediate areas in the central and northern portion of the basin corresponding to the areas with lower rainfall rates during the winter.

\section{Conclusions}

Considering an intra-annual time scale, the results clearly showed significant spatial variability of rainfall. The spatial pattern that occurs for three seasons (summer, fall and spring) was drastically modified during the winter. It is suggested that the causes for the changes in behavior of precipitation are associated with both the regional climatic and the local geomorphological factors. In this respect, a more detailed hydro-climatic study would need to be conducted to assess the influence of regional factors, such as the effects of the South Atlantic Convergence Zone (SACZ) and the cold fronts from southern South America as well as local factors, such as orographic effect caused by the Serra do Mar and Mantiqueira ridges.

In regions of high hidro-climatologic and geomorphological complexities, as those observed in the study area, geostatistics approach proved to be a powerful tool that could allow a more detailed study of the spatial distribution of precipitation. 

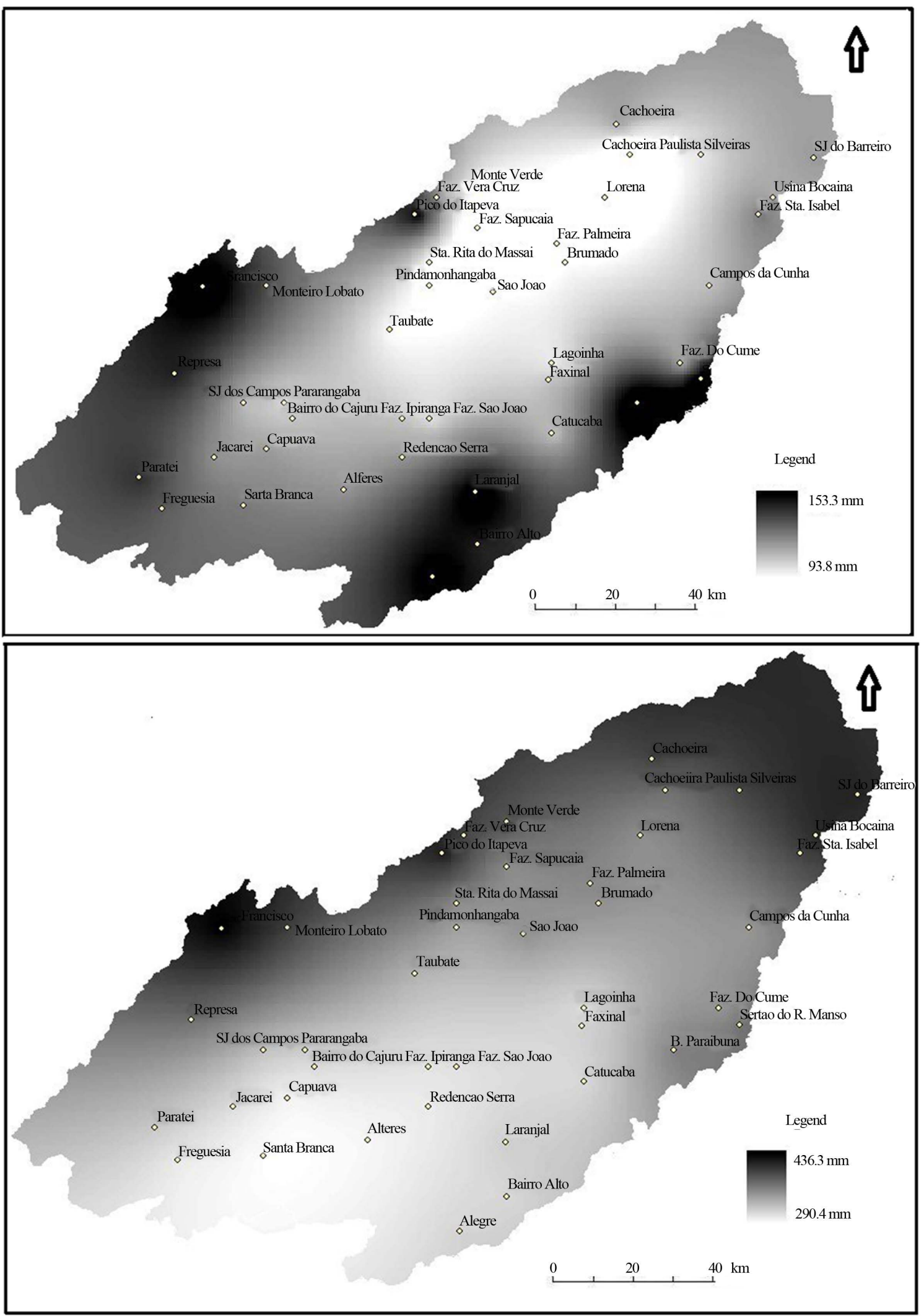

Figure 6. Spatial distribution of rainfall during the winter (above) and the spring (below). The maps identify the station names where the rainfall data was collected. 
The spatial representation of the precipitation can significantly contribute to a better understanding of the rainfall pattern making it possible to guide the water management and the agricultural activities in the region.

\section{References}

[1] de Louis, M., Raventos, J., Gonzales-Hidalgo, J.C., Sanchez, J.R. and Cortina, J. (2000) Spatial Analysis of Rainfall Trends in the Region of Valencia (East Spain). International Journal of Climatology, 20, 1451-1469. http://dx.doi.org/10.1002/1097-0088(200010)20:12<1451::AID-JOC547>3.0.CO;2-0

[2] Syed, K.H., Goodrich, D.C., Myers, D.E. and Sorooshian, S. (2003) Spatial Characteristics of Thunderstorm Rainfall Fields and Their Relation to Runoff. Journal of Hydrology, 271, 1-21. http://dx.doi.org/10.1016/S0022-1694(02)00311-6

[3] Haberlandt, U. (2007) Geostatistical Interpolation of Hourly Precipitation from Rain Gauges and Radar for a LargeScale Extreme Rainfall Event. Journal of Hydrology, 332, 144-157. http://dx.doi.org/10.1016/j.jhydrol.2006.06.028

[4] Basistha, A., Arya, D.S. and Goel, N.K. (2008) Spatial Distribution of Rainfall in Indian Himalayas-A Case Study of Uttarakhand Region. Water Resources Management, 22, 1325-1346. http://dx.doi.org/10.1007/s11269-007-9228-2

[5] Ellouze, M., Azri, C. and Abida, H. (2009) Spatial Variability of Monthly and Annual Rainfall Data over Southern Tunisia. Atmospheric Research, 93, 832-839. http://dx.doi.org/10.1016/j.atmosres.2009.04.005

[6] Ashiq, M.W., Zhao, C., Ni, J. and Akhtar, M. (2010) GIS-Based High-Resolution Spatial Interpolation of Precipitation in Mountain-Plain Areas of Upper Pakistan for Regional Climate Change Impact Studies. Theoretical and Applied Climatology, 99, 239-253. http://dx.doi.org/10.1007/s00704-009-0140-y

[7] Hussain, I., Spock, G., Pilz, J. and Yu, H. (2010) Spatio-Temporal Interpolation of Precipitation during Monsoon Periods in Pakistan. Advances in Water Resources, 33, 880-886. http://dx.doi.org/10.1016/j.advwatres.2010.04.018

[8] Zoccatelli, D., Borga, M., Zanon, F., Antonescu, B. and Stancalie, G. (2010) Which Rainfall Spatial Information for Flash Flood Response Modeling? A Numerical Investigation Based on Data from the Carpathian Range, Romania. Journal of Hydrology, 394, 148-161. http://dx.doi.org/10.1016/j.jhydrol.2010.07.019

[9] del Rio, S., Herrero, L., Fraile, R. and Penas, A. (2011) Spatial Distribution of Recent Rainfall Trends in Spain (19612006). International Journal of Climatology, 31, 656-667. http://dx.doi.org/10.1002/joc.2111

[10] Goovaerts, P. (2000) Geostatistical Approaches for Incorporating Elevation into the Spatial Interpolation of Rainfall. Journal of Hydrology, 228, 113-129. http://dx.doi.org/10.1016/S0022-1694(00)00144-X

[11] Hevesi, J.A., Flint, A. and Istok, J.D. (1992) Precipitation Estimation in Mountainous Terrain Using Multivariate Geostatistics. Journal of Applied Meteorology, 31, 677-688. http://dx.doi.org/10.1175/1520-0450(1992)031<0677:PEIMTU>2.0.CO;2

[12] Kanaroglou, P.S., Soulakellis, N.A. and Sifakis, N.I. (2002) Improvement of Satellite Derived Pollution Maps with the Use of a Geostatistical Interpolation Method. Journal of Geographical Systems, 4, 193-208. http://dx.doi.org/10.1007/s101090100080

[13] Diodato, N. and Russo, F. (2003) A Geostatistic Approach to the Mapping of Rainstorm Hazard in the Sannio District of the Campania Apennines (Southern Italy). Geografia Fisica e Dinamica Quaternaria, 26, 35-40.

[14] Chaplot, V., Saleh, A. and Jaynesc, D.B. (2005) Effect of the Accuracy of Spatial Rainfall Information on the Modeling of Water, Sediment, and $\mathrm{NO}_{3}$-N Loads at the Watershed Level. Journal of Hydrology, 312, 223-234. http://dx.doi.org/10.1016/j.jhydrol.2005.02.019

[15] Buytaert, W., Celleri, R., Willems, P., de Bievre, B. and Wyseure, G. (2006) Spatial and Temporal Rainfall Variability in Mountainous Areas: A Case Study from the South Ecuadorian Andes. Journal of Hydrology, 329, 413-421. http://dx.doi.org/10.1016/j.jhydrol.2006.02.031

[16] Haining, R.P., Kerry, R. and Oliver, M.A. (2010) Geography, Spatial Data Analysis, and Geostatistics: An Overview. Geographical Analysis, 42, 7-31. http://dx.doi.org/10.1111/j.1538-4632.2009.00780.x

[17] Di Piazza, A. (2011) Comparative Analysis of Different Techniques for Spatial Interpolation of Rainfall Data to Create a Serially Complete Monthly Time Series of Precipitation for Sicily, Italy. International Journal of Applied Earth Observation and Geoinformation, 13, 396-408. http://dx.doi.org/10.1016/j.jag.2011.01.005

[18] Longley, P.A., Goodchild, M.E., Maguire, D.J. and Rhind, D.W. (2011) Geographic Information Systems and Science. Wiley, New York.

[19] Grimes, D.I. and Pardo-Iguzquiza, E. (2010) Geostatistical Analysis of Rainfall. Geographical Analysis, 42, $136-160$. http://dx.doi.org/10.1111/j.1538-4632.2010.00787.x

[20] Fujieda, M., Kudoh, T., de Cicco, V. and Carvalho, J.L. (1997) Hydrological Processes at the Subtropical Forest Catchments: The Serra do Mar, Sao Paulo, Brazil. Journal of Hydrology, 196, 26-46. 
http://dx.doi.org/10.1016/S0022-1694(97)00015-2

[21] Forman, R. and Godron, M. (1986) Landscape Ecology. John Wiley \& Sons, New York.

[22] Sao Paulo State Government (2012) Water Resources Situation in the Sao Paulo State [in Portuguese]. Water and Electrical Energy Department (DAEE), Sao Paulo.

[23] Matheron, G. (1963) Principles of Geostatistics. Economic Geology, 58, 1246-1266. http://dx.doi.org/10.2113/gsecongeo.58.8.1246

[24] Isaaks, E.H. and Srivastava, H. (1989) An Introduction to Applied Geostatistics. Oxford University Press, New York.

[25] Webster, R. and Oliver, M. (2007) Geostatistics for Environmental Scientists. John Wiley \& Sons, New York. http://dx.doi.org/10.1002/9780470517277

[26] Goovaert, P. (1997) Geostatistics for Natural Resources Evaluation. Oxford University Press, New York.

[27] Camarinha, P.I., Simoes, S.J.C., Bernardes, G.P. and Trannin, I.C.B. (2012) Correlating Soil Porosity and Respective Geological Unit in Paraiba do Sul Valley, Brazil-A Geostatistical Methodology Proposal. Soils \& Rocks, 35, 209-222.

[28] Matheron, G. (1971) The Theory of Regionalized Variables and Its Applications. Les Cahiers du Centre de Morphologie Mathematique in Fontainebleu, Paris.

[29] Kalkhan, M.A. (2011) Spatial Statistics: GeoSpatial Information Modeling and Thematic Mapping. CRC Press, Boca Raton.

[30] Braga, B.P.F. and Molion, L.C.B. (1999) Assessment of the Impacts of Climate Variability and Change on the Hydrology of South America. In: van Dam, J.C., Ed., Impacts of Climate Change and Climate Variability on Hydrological Regimes, Cambridge University Press, Cambridge, 21-35.

[31] Rao, V.B. and Hada, K. (1990) Characteristics of Rainfall over Brazil: Annual Variations and Connections with the Southern Oscillation. Theoretical and Applied Climatology, 42, 81-91. http://dx.doi.org/10.1007/BF00868215

[32] Simoes, S.J.C. and Barros, A.P. (2007) Regional Climate Variability and Its Effects on Brazil’s 2001 Energy Crisis. Management of Environment Quality, 18, 263-273.

[33] Kousky, V.E. (1985) Atmospheric Circulation Changes Associated with Rainfall Anomalies over Tropical Brazil. Monthly Weather Review, 113, 1951-1957. http://journals.ametsoc.org/doi/abs/10.1175/1520-0493(1985)113\%3C1951\%3AACCAWR\%3E2.0.CO\%3B2

[34] Lemos, C.F. (2000) Characterization and Variability of the Climate in the Paraíba do Sul Valley, Sao Paulo State, Brazil [in Portuguese]. Master Dissertation, Universidade de Taubaté, Taubate. 